\title{
Serratia A Novel Source of Secondary Metabolites
}

\author{
AL-Ghanem M Mai* \\ Department of Micro biology, Heriot-watt University, Scotland
}

Submission: September 10, 2018; Published: September 25, 2018

*Corresponding author: AL-Ghanem M Mai, Department of Micro biology, Heriot-watt University, Edinburgh, Scotland, Email: mai_alghanem@yahoo.com

\begin{abstract}
For many years' microorganisms have been a fascinating area of study. Researchers have realized the importance of these tiny microbes for their ability to produce various useful natural metabolites and compounds with uncultured bacterial species being a rich source of bioactive molecules. Natural metabolites represent an enormous group of organic compounds that do not play essential roles in the normal growth and development of the producing microorganisms but merely confer a selective advantage in complex microbial communities as a biological defense mechanism against predators. The biosynthesis of bacterial secondary metabolites involves multiple enzymatic pathways and reactions brought about by structural diversity which contribute to their highly specific mechanisms of action. Secondary metabolites include isoprenes, oligosaccharides, peptides, polyketides, $\beta$-lactam rings and aromatic compounds. Natural environments are untapped resources of metabolites and encompasses an enormous level of rich ecological biodiversity.
\end{abstract}

Microbial secondary metabolites are attracting attention due to the rise of antibiotics resistance and the growing demand for finding new antibiotics to combat infectious diseases. These compounds are characterized by antibacterial, anticoagulant, anti-inflammatory, anti-fungal, antihelmintic, antiplatelet, antiprotozoal and antiviral activities and act on the cardiovascular, immune and nervous systems with promising possibilities in marine biochemistry, microbiology and biotechnology as well as in pharmaceutical industry, drug development and research. Strains of the genus Serratia inhabit diverse environmental niches with numerous strains considered a reservoir of structurally unique and biologically significant novel secondary metabolites with potent activities. The production of some Serratia secondary metabolites is due to the presence of PKSs genes.

\section{Introduction}

\section{The genus Serratia}

Serratia species of the family Enterobacteriaceae are rod shaped opportunistic Gram-negative bacteria of the c subclass of Proteobacteria and are motile, psychrophilic and facultatively anaerobic [1,2]. They are named after the Italian physicist Serafino Serrati. They are ubiquitous; inhibit a variety of different environmental niches such as; water, soil, plants as well as insects and animals with some associated with food spoilage. Some examples of Serratia include, S. fonticola, S. plymuthica, $S$. marcescens and S. grimesii [3,4]. In laboratory settings, Serratia species can grow on solid media at temperatures ranging from 20 ${ }^{\circ} \mathrm{C}$ to $37^{\circ} \mathrm{C}$ while, in liquid media from $5^{\circ} \mathrm{C}$ to $40^{\circ} \mathrm{C}$ with optimum $\mathrm{pH}$ values of 5-9. Serratia grow in many complex growth media, these include LB, PDA and NA [5-8].

The production of antimicrobial compounds by Serratia is carbon source dependent and highly induced in the presence of nutrients like organic acids and sugars and temperatureregulated with enhanced production at lower temperatures since seasonal variations are a major factor in influencing bacterial metabolic activity $[9,10]$. Some strains of Serratia, in particular $S$. marcescens are human pathogens and the causative agents of contamination in hospital medical devices. S. marcescens associated with nosocomial infections cause pneumonia, septicemia, meningitis, endocarditis and urinary tract infections [11-13].

\section{The red pigment prodigiosin}

For many years now, natural pigments from microbial sources have been studied for their various biological activities. These include anti-oxidants, antifungal and immunosuppressive properties. Prodigiosin is a red non-diffusible, water-insoluble pigment bound to the bacterial cell envelope of some strains of Serratia such as S. plymuthica, S. marcescens and $S$. rubideae. However, the pigment is soluble in organic solvents such as methanol [14-16]. Prodigiosin is an alkaloid secondary metabolite with colours ranging from dark red to pale pink notably on nutrient agar. The majority of reported S. marcescens isolates are of clinical origins and appear non-pigmented in comparison to environmental strains. It is strongly believed that it is temperature related since the optimal temperature for the production of prodigiosin is $28^{\circ} \mathrm{C}[4,17,18]$.

The biosynthesis of prodigiosin is controlled by numerous environmental and physiochemical factors including temperature, oxygen and $\mathrm{pH}$ with maximum production yields achieved in the absence of light. The availability of nutrients in 
media composition like carbon, nitrogen, inorganic phosphate and salts can influence the production of prodigiosin and a number of selective broth media are used for the production of the pigment. These include marine broth, nutrient broth, peptone glycerol broth and sesame seed broth $[16,19]$. The structure of prodigiosin includes three pyrrole rings with two linked together and the third ring attached to a methene forming a pyrrolopyrrole-ethene linkage $[20,21]$. The production of prodigiosin is controlled by a cluster of operonic genes called pigA-O [22].

Prodigiosin appears in the later stages of bacterial growth with no obvious physiological function. Nevertheless, studies speculated on the true biological functions of prodigiosin. These include, acting as an overflow for metabolic cellular waste products in the producing strains, contributing to surface adherence and enhancing bacterial dispersal while other studies claim that it might act as a sink for excess proline such as in Streptomyces [23,24]. The pigment displays anti-malarial, anti-protozoal, anti-fungal activities and a promising potential as an anti-cancer agent due to its potent apoptotic activity in $\mathrm{T}$ and B lymphocytes but low cytotoxicity towards normal cells $[18,25,26]$. Prodigiosin shows bacteriostatic effects with antibacterial activity against numerous pathogenic strains. These include, E. coli, E. faecalis, S. pyogenes and Acinetobacter species $[27,28]$. Prodigiosin extracts purified from $S$. marcescens IBRL USM 84, Serratia marcescens $\mathrm{B}_{2}$ and $S$. marcescens B10 VKM are active against $S$. aureus, $P$. aeruginosa, B. subtilis, B. cereus, salmonella, Shigella, C. albicans, C. utilis, Cryptococcus as well as algal blooms [29,30].

\section{The commercial biotechnological applications of Serratia}

Serratia produce commercially important compounds and enzymes such as lipases, serralysin, chitinases, nucleases, protease, haemolysin and amylases. Some strains of Serratia marcescens secrete chitinase B which is characterized by high thermal stability. It is strongly believed that enzymatic production in Serratia is due to their ability to inhabit various environmental habitats $[2,31,3]$. There is a great interest in the role of Serratia as cost-effective and environmental-friendly bioremediation agents. S. marcescens $\mathrm{B} 742$ synthesizes protease and chitosanase and hydrolyzes the proteinsin SSP protein produced by shrimp shell wastes into water-soluble protein hydrolysates [32,33]. Serratia isolated from soil and water samples encompass unique enzymatic activity and can degrade carboxylic acids (nitriles). Serratia sp. ISTVKR1 biodegradable activity include various chemical compounds and contaminants including organophosphorus pesticides, methyl parathion and p-nitrophenol [34]. Serratia strains isolated from petroleumcontaminated sites in Norway coastline produce hydrocarbondegrading activity with great biotechnological potential in the remediation of oil and petroleum spills.

A novel non-pigmented strain of Serratia isolated from a river in India can hydrolyse urea to ammonia [11,35]. There are numerous studies regarding the important role of Serratia as bio-control agents in agricultural crops management including strawberry, cauliflower and olives. S. plymuthica A30 shows potent activity against the bacterium pathogen Dickeya solani that cause blackleg and soft rot in potato [36-38]. Serratia strains used as environmental bio-control agents include, $S$. proteamaculans and Serratia sp. ANU101 which produce various compounds including the antifungals haterumalides which were the first polyketides to be discovered in Serratia [10,5,39].

The novel strain Serratia marcescens B4A produces potent antifungal compounds and inhibit the growth of insects and plant pathogens such as Rhizoctonia solani and Alternaria raphanin. The following strains of Serratia, Serratia marcescens, Serratia plymuthica, Serratia sp. SY5, Serratia fonticola AU-P3 and Serratia fonticola DSM 4576T are plant growth promoting bacteria. They enhance crop yields and ecological balance in the agroecosystem by facilitating the uptake of nutrients from the environment. They also produce secondary metabolites such as siderophores and phytohormone and protect the plants against pathogenic infections [39-41]. Some strains of Serratia including, Serratia plymuthica HRO-C48 produce the halogenated secondary metabolite pyrrolnitrin which is a promising agricultural fungicide [42-44]. Serratia nematodiphila DSM 21420T is a biological pest control agent and produce potent insecticidal Sep proteins (SepA, SepB, SepC).

A full genome sequence of the strain showed gene clusters encoding enzymes contributing to antimicrobial production [45]. The following strains of Serratia including, S. plymuthica 4Rx13, S. marcescens Db11, S. odorifera DSM 4582 and S. plymuthica PRI-2C produce volatile organic compounds VOCs including dimethyl trisulfide, sodorifen and methanethioland terpenoids $[46,17,47]$. These compounds have cytotoxic broad bacteriostatic inhibitory activity against various pathogenic bacteria and fungi, fruit flies and nematodes $[48,49]$.

\section{Serratia a novel source of antimicrobial compounds}

Serratia produce secondary metabolites with potent antibacterial, anti-fungal as well as anticancer activities [9]. Some strains of Serratia have a highly species-specific secretion-system (type VI) also known as T6SS which enables the production of broad-spectrum bioactive compounds. This system facilitates the production of antibacterial toxins and selfprotecting bacteriophage contained proteins that contribute to virulence against competitors and even related Serratia strains $[36,50,51]$. The production of bioactive secondary metabolites in Serratia is due to Quorum Sensing (QS) [52,17]. QS regulates gene expression in many Gram-negative bacteria in response to environmental selective pressure like the depletion of nutrients and influences population density by the production of N-Acyl Homoserine Lactone (AHL) molecules [29,53]. AHL are intercellular auto-inducer diffusible signaling molecules biosynthesized by the enzyme LuxI and regulates the production 
of antimicrobials, antibiotics, enzymes and plant growth promoting compounds as well as contributing to motility, sporulation, virulence and biofilm formation $[4,54]$.

There are various studies regarding the antimicrobial metabolites of Serratia. The culture supernatant of Serratia marcescens 2170 have strong cytotoxic activity against cancer cell lines [55]. Also, Serratia sp. strain American Type Culture Collection 39006 produces the broad spectrum $\beta$-lactam antibiotic Carbapenem. S. marcescens 274 and Serratia 39006 secrete haemolysin, prodigiosin [56,24]. Some strains of $S$. marcescens such, as $S$. marcescens strain NSK-1and S. marcescens IBBPo15 produce the lipopeptide compounds, serrawettins synthesized by polyketide synthases. Serrawettins are broad spectrum antibacterial bio-surfactants and potent anticancer agents against T-cell leukemia and Burkittis lymphoma [17]. Recent research regarding S. plymuthica A153 and S. marcescens MSU97 revealed the production of the antifungal compound antioomycete, the anticancer agent haterumalide and the antibiotic andrimid.

The latter inhibits the growth of Salmonella enteritidis, Yersinia enterolitica, Vibrio harveyi and Enterococcus [41,13]. $S$. grimesii and S. proteamaculans produce anti-cancer metabolites active against human larynx carcinoma [9]. Some Serratia produce the exoenzymes oocydin A and bacteriocins [54]. $S$. marcescens Db10 secretes the antibacterial toxins Ssp1 and Ssp2 and produces self-resistance proteins as a protection mechanism from its own toxins [42,37]. Strains of Serratia such as S. plymuthica, Serratia sp. strain V4 and S. plymuthica RVH1 produce zeamine antibiotics which have broad spectrum bactericidal activity against multidrug resistant bacteria and yeast. Zeamines cause membrane permeabilization through hydrophobic interactions with phospholipid layers and have cyto-toxic activities against human cancer cell lines [57-61].

\section{References}

1. Grimont PA, Grimont F (1978) The genus Serratia. Annual Review of Microbiology 32: 221-248.

2. Bentley R (1999) Secondary metabolite biosynthesis: the first century. Crit Rev Biotechnol 19: 1-40.

3. Williamson NR, Simonsen HT, Ahmed RA, Goldet G, Slater H, et al. (2005) Biosynthesis of the red antibiotic, prodigiosin, in Serratia: identification of a novel 2-methyl-3-n-amylpyrrole (MAP) assembly pathway, definition of the terminal condensing enzyme, and implications for undecylprodigiosin biosynthesis in Streptomyces. Mol Microbiol56(4): 971-989.

4. Weise T, Thürmer A, Brady S, Kai M, Daniel R, et al. (2014) VOC emission of various Serratia species and isolates and genome analysis of Serratia plymuthica 4Rx13. FEMS Microbiol Lett 352(1): 45-53.

5. Stock I, Burak S, Sherwood KJ, Gruger T, Wiedemann B (2003) Natural antimicrobial susceptibilities of strains of 'unusual' Serratia species: S. ficaria, S. fonticola, S. odorifera, S. plymuthica and S. rubidaea. J Antimicrob Chemother51(4): 865-85.

6. Houdt RV, Givskov M, Michiels CW (2007) Quorum sensing in Serratia. FEMS Microbiol Rev 31(4): 407-424.
7. Houdt RV, Lelie DVD, Izquierdo JA, Aertsen A, Masschelein J, et al. (2014) Genome Sequence of Serratia plymuthica RVH1, Isolated from a Raw Vegetable-Processing Line. Genome Announcements 2(1). pii: e00021-14.

8. Stancu MM (2016) Response Mechanisms in Serratia marcescens IBBPo15 During Organic Solvents Exposure. Curr Microbiol 73(6): 755-765.

9. Matilla MA, Nogellova V, Morel B, Krell T, Salmond GP (2016) Biosynthesis of the acetyl-CoA carboxylase-inhibiting antibiotic, andrimid, in Serratia is regulated by $\mathrm{Hfq}$ and the LysR-type transcriptional regulator, AdmX. Environ Microbiol 18(11): 36353650.

10. Adam E, Müller H, Erlacher A, Berg G (2016) Complete genome sequences of the Serratia plymuthica strains 3Rp8 and 3Re4-18, two rhizosphere bacteria with antagonistic activity towards fungal phytopathogens and plant growth promoting abilities. Stand Genomic Sci 11(1): 61.

11. Ashelford KE, Fry JC, Bailey MJ, Day MJ (2002) Characterization of Serratia isolates from soil, ecological implications and transfer of Serratia proteamaculans subsp. quinovora Grimont et al. 1983 to Serratia quinivorans corrig, sp. Nov. Int J Syst Evol Microbiol 52 (pt 6): 2281-22899.

12. Bonnin RA, Didi J, Ergani A, Lima S, Thierry Naas T (2017) ChromosomeEncoded Broad-Spectrum Ambler Class A B -Lactamase RUB-1 from Serratia rubidaea. Antimicrobial Agents and Chemotherapy 61: 1-6.

13. Darshan N, Manonmani HK (2015) Prodigiosin and its potential applications. Journal of Food Science and Technology 52(9): 53935407.

14. Elkenawy NM, Yassin AS, Elhifnawy HN, Amin MA (2017) Optimization of prodigiosin production by Serratia marcescens using crude glycerol and enhancing production using gamma radiation. Biotechnol Rep (Amst) 14: 47-53.

15. Jafarzade M, Yahya NA, Shayesteh F, Usup G, Ahmad A (2013) Influence of culture conditions and medium composition on the production of antibacterial compounds by marine Serratia sp. WPRA3. J Microbiol 51(3): 373-379.

16. Darshan N, Manonmani HK (2015) Prodigiosin and its potential applications. J Food Sci Technol 52(9): 5393-5407.

17. Su C, Xiang Z, Liu Y, Zhao X, Sun Y (2016) Analysis of the genomic sequences and metabolites of Serratia surfactantfaciens sp. nov. YD25T that simultaneously produces prodigiosin and serrawettin W2. BMC Genomics 17(1): 1-19.

18. Faraag AH, El-Batal AI, El-Hendawy HH (2017) Characterization of prodigiosin produced by Serratia marcescens strain isolated from irrigation water in Egypt. Nature and Science 15: 55-68.

19. Vleesschauwer DD, Hofte M (2007) Using Serratia plymuthica to control fungal pathogens of plants. CAB Reviews: Perspectives in Agriculture, Veterinary Science, Nutrition and Natural Resources 2:112.

20. Moons P, Van Houdt R, Aertsen A, Vanoirbeek K, Engelborghs Y (2006) Role of Quorum Sensing and Antimicrobial Component Production by Serratia plymuthica in Formation of Biofilms, Including Mixed Biofilms with Escherichia coli. Appl Environ Microbiol 72(11): 7294-7300.

21. Ibrahim D, Nazari TF, Kassim J, Lim SH (2014) Prodigiosin - an antibacterial red pigment produced by Serratia marcescens IBRL USM 84 associated with a marine sponge Xestospongia testudinaria. J App Pharm Sci 4(10): 1-6.

22. Ruiz B, Chávez A, Forero A, García-Huante Y, Romero A, et al. (2010) Production of microbial secondary metabolites: regulation by the carbon source. Critical Reviews in Microbiology 36(2): 146-167. 


\section{Advances in Biotechnology \& Microbiology}

23. Harris AK, Williamson NR, Slater H, Cox A, Abbasi S, et al. (2004) The Serratia gene cluster encoding biosynthesis of the red antibiotic, prodigiosin, shows species- and strain-dependent genome context variation. Frontiers in Microbiology 150(Pt 11): 3547-3560.

24. Fineran PC, Slater H, Everson L, Katie Hughes K, Salmond GPC (2005) Biosynthesis of tripyrrole and b-lactam secondary metabolites in Serratia: integration of quorum sensing with multiple new regulatory components in the control of prodigiosin and carbapenem antibiotic production. Mol Microbiol 56(6): 1495-1517.

25. Bentley R (1999) Secondary metabolite biosynthesis: the first century. Crit Rev Biotechnol 19(1): 1-40.

26. Slater H, Crow M, Everson L, Salmond GPC (2003) Phosphate availability regulates biosynthesis of two antibiotics, prodigiosin and carbapenem, in Serratia via both quorum-sensing-dependent and -independent pathways. Molecular Microbiology, 47: 303-320.

27. Lapenda JC, Silva PA, Vicalvi MC, Sena KX, Nascimento SC (2015) Antimicrobial activity of prodigiosin isolated from Serratia marcescens UFPEDA 398. World J Microbiol Biotechnol 31(2): 399-406.

28. Wang Z, Li B, Zhou L, Yu S, Su Z, et al. (2016) Prodigiosin inhibits Wnt/ $\beta$-catenin signaling and exerts anticancer activity in breast cancer cells. Proc Natl Acad Sci U S A 113(46): 1350-1355.

29. Thomson NR, Crow MA, Mc Gowan SJ, Cox A, Salmond GP (2000) Biosynthesis of carbapenem antibiotic and prodigiosin pigment in Serratia is under quorum sensing control. Mol Microbiol 36(3): 539556

30. Pore TS, Khanolkar AB, Nadaf NH (2016) Production, purification, identification of prodigiosin from Serratia sp. and its antimicrobial activity. Research journal of life sciences, bioinformatics, pharmaceutical and chemical science 1-12

31. Abdou AM (2003) Purification and Partial Characterization of Psychrotrophic Serratia marcescens Lipase. J Dairy Sci 86(1): 127-132.

32. Gaeseidnes S, Synstad B, Jia X, Kjellesvik H, Vriend G, et al. (2003) Stabilization of a chitinase from Serratia marcescens by Gly®Ala and Xxx®Pro mutations. Protein Eng 16(11): 841 -846.

33. Zhang H, Fang J, Deng Y, Zhao Y (2014) Optimized production of Serratia marcescens B742 mutants forpreparing chitin from shrimp shells powders. Int J Biol Macromol 69: 319-328.

34. Gupta A, Thakur IS (2015) Biodegradation of wastewater organic contaminants using Serratia sp. ISTVKR1 isolated from sewage sludge. Biochemical Engineering Journal 102: 115-124.

35. Frankowski J, Lorito M, Scala F, Schmid R, Berg G, et al. (2001) Purification and properties of two chitinolytic enzymes of Serratia plymuthica HRO-C48. Arch Microbiol 176(6): 421-426.

36. Petersen LM, Tisa LS (2013) Friend or foe? A review of the mechanisms that drive Serratia towards diverse lifestyles. Canadian Journal of Microbiology 59(9): 627-640.

37. Matilla MA, Salmond GP (2014) Bacteriophage фMAM1, a Viunalikevirus, is a Broad-Host-Range, High-Efficiency Generalized Transducer That Infects Environmental and Clinical Isolates of the Enterobacterial Genera Serratia and Kluyvera. Appl Environ Microbiol 80(20): 6446-6457.

38. Czajkowski R, Wolf JM (2012) Draft Genome Sequence of the Biocontrol Strain Serratia plymuthica A30, Isolated from Rotting Potato Tuber Tissue. Journal of Bacteriology 194: 6999-7000.

39. Lim YL, Yong D, Ee R, Krishnan T, Tee KK (2015) Complete genome sequence of Serratia fonticola DSM 4576T a potential plant growth promoting bacterium. J Biotechnol 214: 43-44

40. Zarei M, Aminzadeh S, Zolgharnein H, Safahieh A, Daliri M (2011) Characterization of a chitinase with antifungal activity from a native Serratia marcescens B4A. Braz J Microbiol 42(3): 1017-1029.
41. Matilla MA, Drew A, Udaondo Z, Krell T, Salmond GP (2016) Genome Sequence of Serratia plymuthica A153, a Model Rhizobacterium for the Investigation of the Synthesis and Regulation of Haterumalides, Zeamine, and Andrimid. Genome Announcements 4(3): 1-2.

42. Cleto S, Auwera GVD, Almeida C, Vieira MJ, Vlamakis H, et al. (2014) Genome Sequence of Serratia plymuthica V4. Genome Announc 2(3): e00340-14.

43. Liu X, Bimerew M, Ma Y, Müller H, Ovadis M (2007) Quorum-sensing signaling is required for production of the antibiotic pyrrolnitrin in a rhizospheric biocontrol strain of Serratia plymuthica. FEMS Microbiol Lett 270(2): 299-305

44. Bhadra B, Roy P, Chakraborty R (2005) Serratia ureilytica sp. nov., a novel urea-utilizing species. Int J Syst Evol Microbiol. 55(Pt 5): 21552158.

45. KwakY, Khan AR, Shin JH (2015) Genome sequence of Serratia nematodiphila DSM 21420T, a symbiotic bacterium from entomopathogenic nematode. J Biotechnol 193: 1-2.

46. Popova AA, Koksharova OA, Lipasova VA, Zaitseva JV, Zhukotskaya OAK, et al. (2014) Inhibitory and Toxic Effects of Volatiles Emitted by Strains of Pseudomonas and Serratia on Growth and Survival of Selected Microorganisms, Caenorhabditis elegans, and Drosophila melanogaster. BioMed Research International 1-11.

47. Neupane S, Finlay RD, Alström S, Goodwin L, Kyrpides NC, et al. (2012) Complete genome sequence of Serratia plymuthica strain AS12. Stand Genomic Sci 6(2): 165-173.

48. Dang NP, Landfald B, Willassen NP (2015) Biological surface-active compounds from marine bacteria. Environ Technol 37(9): 1151-1158.

49. Schmidt R, Jager V, Zühlke D, Wolff C, Bernhardt J (2017) Fungal volatile compounds induce production of the secondary metabolite Sodorifen in Serratia plymuthica PRI-2C. Sci Rep 7(1): 862.

50. Hellberg JEEU, Matilla MA, Salmond GPC (2015) The broad-spectrum antibiotic, zeamine, kills the nematode worm Caenorhabditis elegans. Front Microbiol 6: 137

51. Fritsch MJ, Trunk K, Diniz JA, Guo M, Trost M, et al. (2013) Proteomic Identification of Novel Secreted Antibacterial Toxins of the Serratia marcescens Type VI Secretion System. T Mol Cell Proteomics 12(10): 2735-2749.

52. Chernin L, Toklikishvili N, Ovadis M, Kim S, Ben-Ari J, et al. (2011) Quorum-sensing quenching by rhizobacterial volatiles. Environ Microbiol Rep 3(6): 698-704.

53. Wencewicz TA (2016) New antibiotics from Nature's chemical inventory. Bioorg Med Chem 24(24): 6227-6252.

54. Sánchez S, Chávez A, Forero A, García-Huante Y, Romero A, et al. (2010) Carbon source regulation of antibiotic production J Antibiot (Tokyo) 63(8): 442-459.

55. Coulthurst SJ, Kurz CL, Salmond GPC (2004) luxS mutants of Serratia defective in autoinducer-2-dependent 'quorum sensing' show straindependent impacts on virulence and production of carbapenem and prodigiosin. Microbiology 150(Pt 6): 1901-1910.

56. Montaner B, Navarro S, Piqué M, Vilaseca M, Martinell M, et al. (2000) Prodigiosin from the supernatant of Serratia marcescens induces apoptosis in haematopoietic cancer cell lines. Br J Pharmacol 131(3): 585-593.

57. Masschelein J, Mattheus W, Gao LJ, Moons P, Van Houdt R (2013) A PKS/NRPS/FAS Hybrid Gene Cluster from Serratia plymuthica RVH1 Encoding the Biosynthesis of Three Broad Spectrum, Zeamine-Related Antibiotics. PLoS ONE 8(1): 1-11.

58. Masschelein J, Clauwers C, Stalmans K, Nuyts K, De Borggraeve W (2015) The Zeamine Antibiotics Affect the Integrity of Bacterial Membranes. Appl Environ Microbiol 81(3): 1139-1146. 
59. Akele FA, Tisa LS, Cooper VS, Hatcher PJ, Abebe E (2015) Genome sequence and comparative analysis of a putative entomopathogenic Serratia isolated from Caenorhabditis briggsae. BMC Genomics 16: 531.

60. Gallo A, Ferrara M, Perrone G (2013) Phylogenetic Study of Polyketide
Synthases and Nonribosomal Peptide Synthetases Involved in the Biosynthesis of Mycotoxins. Toxins 5(4): 717-742.

61. Gallo A, Ferrara M, Perrone G (2013) Phylogenetic Study of Polyketide Synthases and Nonribosomal Peptide Synthetases Involved in the Biosynthesis of Mycotoxins. Toxins (Basel) 5(4): 717-742.

\section{Your next submission with Juniper Publishers will reach you the below assets}

- Quality Editorial service

- Swift Peer Review

- Reprints availability

- E-prints Service

- Manuscript Podcast for convenient understanding

- Global attainment for your research

- Manuscript accessibility in different formats

( Pdf, E-pub, Full Text, Audio)

- Unceasing customer service

Track the below URL for one-step submission https://juniperpublishers.com/online-submission.php 